\title{
Rancang Bangun Aplikasi Total Productive Maintenance (TPM) Berbasis Android
}

\author{
Dimas Irwan Aji Andriyono(), Ahmad Fitriansyah ${ }^{*}{ }^{* 2)}$, Eka Satryawati ${ }^{3)}$ \\ 12)3) Program Studi Sistem Informasi, Universitas Mohammad Husni Thamrin \\ ${ }^{*}$ Correspondence Author: hafaskom@gmail.com, Jakarta, Indonesia \\ DOI: https://doi.org/10.37012/jtik.v6i2.235
}

\begin{abstract}
Abstrak
Dalam era revolusi industri 4.0, perusahaan terus dituntut untuk melakukan inovasi dengan memberi kesempatan kepada seluruh karyawannya untuk turut serta membangun dan membuat ide-ide baru di perusahaan. Salah satunya adalah inovasi dalam kegiatan Total Productive Maintenance (TPM). Inovasi ini diharapkan membantu meningkatkan performa mesin-mesin produksi yang ada di perusahaan. Kendala yang dihadapi adalah minimnya pengolahan data administrasi total productive maintenance. Data tersebut kurang detail sehingga menjadi salah satu masalah dalam mengembangkan inovasi TPM. Penelitian ini akan ikut membantu menyelesaikan permasalah tersebut dengan membangun aplikasi yang dapat mengolah data TPM secara sistematis dan informatif. Penelitian ini menggunakan metode analisis software development life cycle (SDLC) untuk menganalisa sistem yang dibutuhkan mulai dari perencanaan, analisis, perancangan, penerapan, dan pemeliharaan. Sistem yang dibangun menggunakan Bahasa pemrograman Java dan SQLlite untuk databasenya, Android studio versi 3.5 untuk desain dan unified modelling language (UML) untuk pemodelan sistemnya. Hasil penelitian ini berupa aplikasi B7TPM berbasis android yang hanya bisa di akses secara internal di lingkungan perusahaan.
\end{abstract}

Kata Kunci: Total Productive Maintenance, Aplikasi, Android

\begin{abstract}
In the era of the industrial revolution 4.0, companies continue to be demanded to innovate by giving opportunities to all of their employees to participate in developing and creating new ideas in the company. One of them is innovation in Total Productive Maintenance (TPM) activities. This innovation is expected to help improve the performance of production machines in the company. The obstacle faced is the lack of detailed processing data of administrative less productive maintenance which is one of the problems in developing innovation in TPM. This research will help solve this problem by building applications that can process TPM data in a systematic and informative manner. This research uses the analysis method of the software development life cycle (SDLC) to analyze the systems needed ranging from planning, analysis, design, implementation, and maintenance. The system is built using the Java programming language and SQLLite for its database, Android studio version 3.5 for design, and unified modeling language (UML) for modeling the system. The results of this study are in the form of an Android-based B7TPM application that can only be accessed internally in a corporate environment.
\end{abstract}

Keywords: Total Productive Maintenance, Application, Android

\section{PENDAHULUAN}

Perkembangan teknologi di era modernisasi dan globlalisasi telah membuat hidup manusia menjadi lebih mudah. Dengan semakin berkembangnya teknologi informasi ini, kebutuhan akan informasi yang berkualitas sangatlah diperlukan. Dunia industri manufaktur di Indonesia turut berlomba-lomba menerapkan perkembangan teknologi agar tidak tertinggal serta semakin maju dan berkembang dengan menerapkan konsep revolusi industri. PT Bintang Toedjoe sebagai salah satu anak perusahaan PT Kalbe Farma Tbk, yang bergerak 
di bidang industri Farmasi juga baru memulai untuk merancang, dan membangun serta menerapkan konsep revolusi industri 4.0 tersebut agar dapat tetap bersaing di pasar Global dan Internasional. Project baru dari PT Bintang Toedjoe adalah dengan membentuk tim untuk mengadakan project Total Productive Maintenance (TPM) yang akan diterapkan di mesin-mesin industri yang mereka miliki.

TPM adalah suatu sistem yang digunakan untuk memelihara dan meningkatkan kualitas produksi melalui perawatan perlengkapan dan peralatan kerja seperti Mesin dan alat-alat kerja. Fokus utama TPM adalah untuk memastikan semua perlengkapan dan peralatan produksi beroperasi dalam kondisi terbaik sehingga menghindari terjadinya kerusakan ataupun keterlambatan dalam proses produksi. TPM bertujuan untuk memaksimalkan efektivitas dari fasilitas yang digunakan dalam industri tersebut, yang tidak hanya dialamatkan pada perawatan saja tetapi pada semua aspek dari operasi dan instalasi dari fasilitas produksi termasuk juga didalamnya peningkatan motivasi dari karyawan.

Selama ini proses administrasi TPM masih dilakukan secara manual, seperti penulisan pada form red text dan white text yang berpotensi robek maupun kotor jika terkena oli atau debu pada saat proses pembersihan dalam aktivitas TPM. Untuk itu dirasa perlu dibuatkan aplikasi khusus berbasis android agar membantu dalam administrasi dan pendataan TPM. Android merupakan sebuah sistem operasi untuk perangkat smartphone. Android dipilih karena target dari aplikasi TPM ini adalah agar bisa terinstal di smartphone masing-masing peserta TPM dan juga tablet yang ada pada setiap ruang produksi di perusahaan.

Aplikasi TPM (total productive maintenance) sendiri sudah pernah di teliti oleh peneliti sebelumnya. Dalam penelitian Aplikasi TPM di PT Hexparm Jaya Laboratories (Danuseputro, 2016) terbukti bahwa aplikasi dapat meningkatkan efektifitas mesin produksi di line 3 yang sering bermasalah dan dapat memangkas waktu yang terbuang yang disebabkan oleh mesin dan reject produk. Penelitian selanjutnya tentang penerapan TPM di PT Asia Protendo Graha untuk meningkatkan efisiensi dan efektivitas pada mesin injection molding yang sering mengalami kerusakan atau breakdown sehingga mengakibatkan rendahnya tingkat produktivitas dari mesin tersebut (Utomo \& Alghofari, 2018). Dari penelitian-penelitian tersebut, kegiatan TPM sendiri penerapannya sudah berhasil, tetapi karena sistem administrasi yang masih manual menimbulkan masalah baru, diantaranya belum ada label tag peringatan jika mesin sedang dalam kegiatan TPM, kemudian banyak kertas dokumen yang sering kotor bahkan robek dikarenakan bersamaan waktu pengisian dan aktifitas pembersihan di mesin produksinya. Untuk itu perlu di kembangkan lagi agar mempermudah dan lebih efisien penerapannya terutama untuk administrasi TPM ini. 
Pengertian aplikasi sendiri merupakan sebuah transformasi dari sebuah permasalahan atau pekerjaan berupa hal yang sulit dipahami menjadi lebih sederhana, mudah dan dapat dimengerti oleh pengguna. Sehingga dengan adanya aplikasi, sebuah permasalahan akan terbantu lebih cepat dan tepat. Aplikasi sendiri memiliki beberapa jenis yaitu berbasis desktop, berbasis web dan berbasis mobile.

Perawatan adalah segala kegiatan yang penting dengan tujuan untuk menghasilkan produk yang baik atau untuk mengembalikan kedalam keadaan yang memuaskan. Perawatan atau maintenance dapat didefinisikan sebagai sebuah aktivitas yang dibutuhkan untuk menjaga atau mempertahankan kualitas pemeliharaan suatu fasilitas agar fasilitas tersebut dapat berfungsi dengan baik dalam kondisi siap pakai (Sudrajat \& Rahmatullah, 2020). Maintenance sendiri ada tiga jenis yaitu : Pemeliharaan pencegahan (preventive maintenance), Pemeliharaan korektif (corrective maintenance), Perawatan Breakdown.

Total Productive Maintenance (TPM) merupakan suatu aktivitas perawatan yang mengikut sertakan semua elemen dari perusahaan, yang bertujuan untuk menciptakan suasana kritis (critical mass) dalam lingkungan industri guna mencapai zero defect dan zero accident (Kurniawan, 2013). TPM adalah suatu metode yang bertujuan untuk memaksimalkan efisiensi penggunaan peralatan, dan memantapkan sistem perawatan preventif yang dirancang untuk keseluruhan peralatan dengan mengimplementasikan suatu aturan dan memberikan motivasi kepada seluruh bagian yang berada dalam suatu perusahaan tersebut, melalui peningkatan kompetensi dari seluruh anggota yang terlibat mulai dari manejemen puncak sampai kepada level bawah.

\section{METODE}

Metode pelaksanaan kegiatan merupakan cara ilmiah untuk mendapatkan data dengan tujuan dan kegunaan tertentu. Metode yang digunakan dalam penelitian ini yaitu :

1. Metode Wawancara, dalam hal ini penulis menanyakan langsung hal-hal dan administrasi data yang berkaitan dengan project Total Productive Maintenance yang ada pada PT Bintang Toedjoe Jakarta kepada supervisor teknik dan supervisor produksi.

2. Metode Observasi, dengan melakukan pengecekan dan mengevaluasi atas informasi yang didapat dari wawancara sehingga betul-betul memahami permasalahan yang ada sesuai dengan keadaan yang sebenarnya. Observasi dilakukan terhadap proses perawatan mesin secara berkala dan juga administrasi mesin produksi yang selama ini dilakukan pada saat proses TPM berlangsung serta melakukan pendataan pada mesin produksi yang di gunakan untuk proses TPM. 
3. Metode Penelitian Pustaka, dengan mempelajari literatur-literatur dan referensi yang berkaitan dengan permasalahan yang dihadapi. Metode ini juga merupakan metode pengumpulan data yang diarahkan kepada pencarian data dan informasi melalui dokumen-dokumen, baik dokumen tertulis, foto-foto, gambar, maupun dokumen elektronik yang dapat mendukung dalam proses penulisan.

\section{HASIL DAN PEMBAHASAN}

Prosedur yang berjalan saat ini, sebelum operator produksi mengoperasikan mesin produksi dan melakukan proses produksi, hal pertama yang dilakukan operator produksi adalah memastikan mesin aman dengan dilakuannya kegiatan total productive maintenance selama 15 menit. Jika terjadi kerusakan mesin saat proses produksi berlangsung atau pada saat kegiatan total productive maintenance, operator produksi segera menekan emergency yang ada di mesin dan melaporkan kerusakan mesin ke admin produksi. Admin produksi membuat form WR (work request) permintaan perbaikan mesin dan diserahkan ke admin tehnik. WR permintaan perbaikan mesin akan di cek oleh admin tehnik dan jika disetujui maka admin tehnik membuat form WO (work order). Setelah itu form work order harus di print, dan selanjutnya akan di serahkan ke spv teknik terkait. Setelah diicek oleh spv teknik dan jika disetujui, WO (work order) akan diberikan ke teknisi yang bertugas sesuai dengan kerusakan mesin produksi tersebut. Setelah di terima teknisi yang bertugas di area tersebut, maka WO akan di cek untuk memastikan ada kebutuhan barang sparepart atau tidak, jika butuh maka teknisi harus membuat PBJT (permintaan barang dan jasa teknisi) atau form permintaan barang kepada admin sparepart, tetapi jika tidak membutuhkan part maka WO akan langsung di kerjakan oleh teknisi. Setelah selesai perbaikan, teknisi melapor ke admin produksi dan minta paraf serta serah terima mesin yang sudah selesai diperbaiki. Selanjutkan admin produksi mengembalikan dan menyerahkan WO yang telah selesai ke spv teknik. Spv teknik melakukan pengecekan ulang untuk memastikan mesin yang telah selesai di perbaiki tadi. Jika sudah selesai WO bisa ditutup dan di paraf oleh spv teknik dan dikembalikan ke admin teknik untuk disimpan sebagai dokumen administrasi kerusakan mesin produksi.

Berdasarkan hasil analisis sistem, permintaan perbaikan work request dan work order pada PT Bintang Toedjoe Jakarta masih ditemukan permasalahan yang dihadapi saat ini yaitu :

1. Sering terjadi kesalahpahaman ataupun kesasalahan komunikasi antar operator mesin produksi sewaktu pergantian shift mengenai status mesin produksi tersebut karena kurangnya informasi yang di terima tentang status mesin apakah sudah selesai perbaikan atau belum. 
2. Hal yang sama juga terjadi terhadap beberapa karyawan di divisi engineering setelah pergantian shift dikarenakan kurangnya informasi secara detail dan banyak mesin yang sama sehingga terkadang salah dalam perbaikan mesin karena tidak ada identitas kerusakan di mesin tersebut.

3. Kurang efektifnya informasi yang diterima admin produksi dan sering terjadinya salah komunikasi antara departement produksi dengan departement engineering mengenai status mesin dan jadwal perawatan mesin.

4. Ada beberapa karyawan baru yang sering salah menganalisa maupun kurang begitu paham mengenai kerusakan yang terjadi pada mesin-mesin produksi di PT Bintang Teodjoe.

Untuk mengatasi permasalahan yang dihadapi dan untuk memaksimalkan kegiatan TPM serta mengurangi kesalahpahaman antar operator maupun antar divisi tersebut akan dilakukan perancangan aplikasi sebagai berikut :

1. Aplikasi berbasis android yang digunakan secara internal di lingkungan PT Bintang Toedjoe yang diberi nama B7TPM untuk membantu administrasi di mesin produksi dan memberikan informasi output berupa label yang telah di isi dari aplikasi yang berfungsi sebagai identitas dan juga status mesin produksi tersebut.

2. Mengintegrasikan data-data mesin produksi ke dalam database untuk mempermudah dan mempercepat dalam proses pencarian data yang dilakukan di dalam kegiatan aktivitas TPM di PT Bintang Toedjoe Jakarta.

Rancangan fungsional aplikasi yang diusulkan dapat dilihat pada diagram usecase sebagai berikut : 

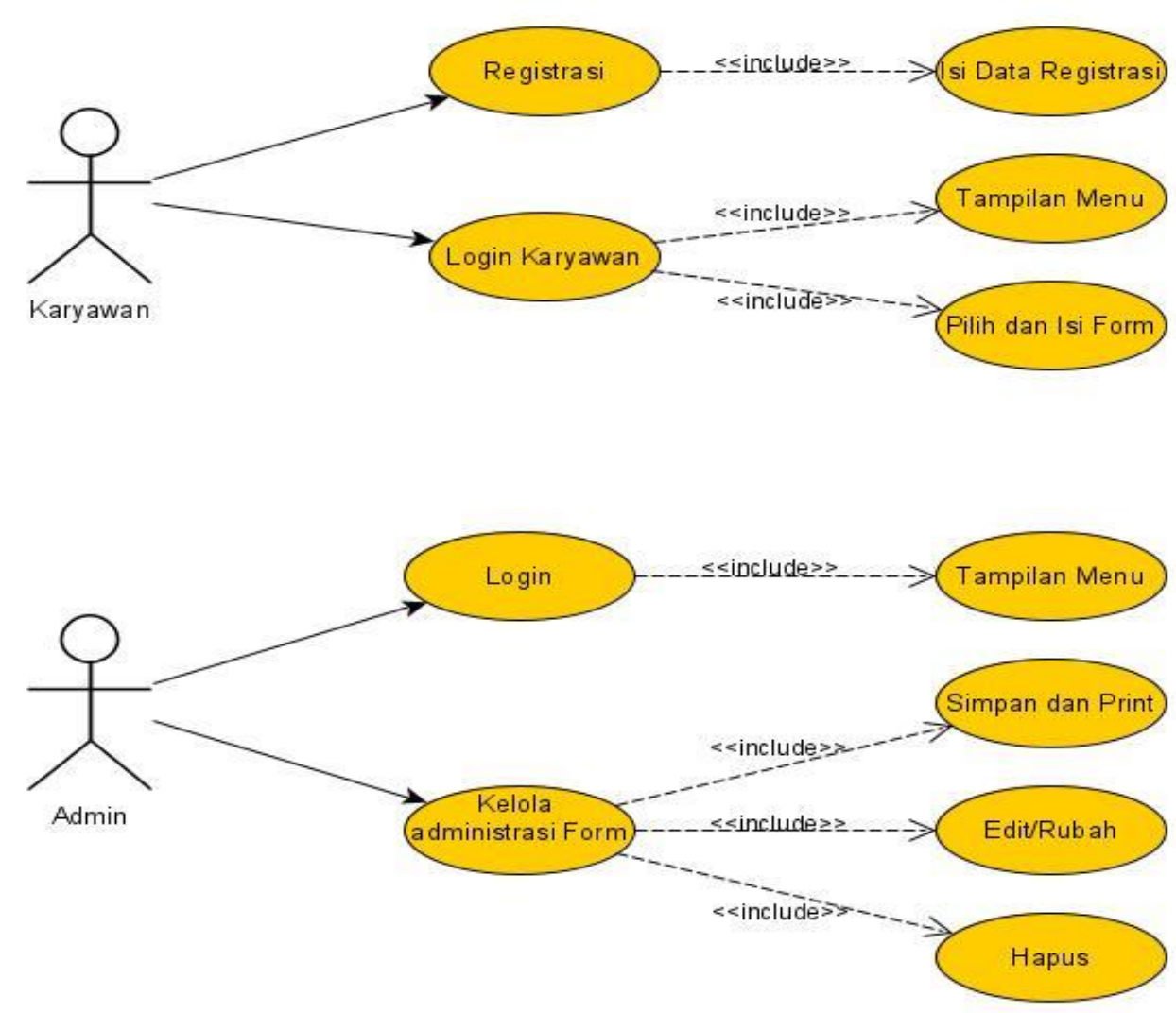

Gambar 1. Use Case Diagram Aplikasi B7TPM

Aplikasi ini diimplementasikan untuk sistem operasi android menggunakan bahasa pemrograman Java. Berikut ini merupakan gambaran tampilan menu-menu yang ada pada aplikasi B7TPM:

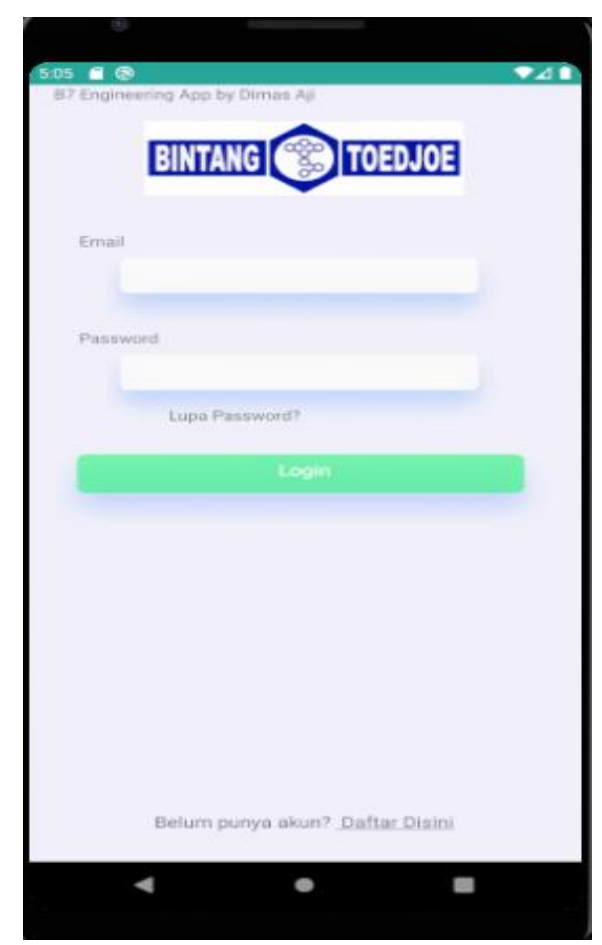

Gambar 2. Tampilan Halaman Login 
Tampilan Login ini akan muncul otomatis setelah tampilan splash screen dan di sini user diminta untuk mengisi email serta password yang digunakan untuk mengakses menu-menu yang ada di aplikasi B7TPM.

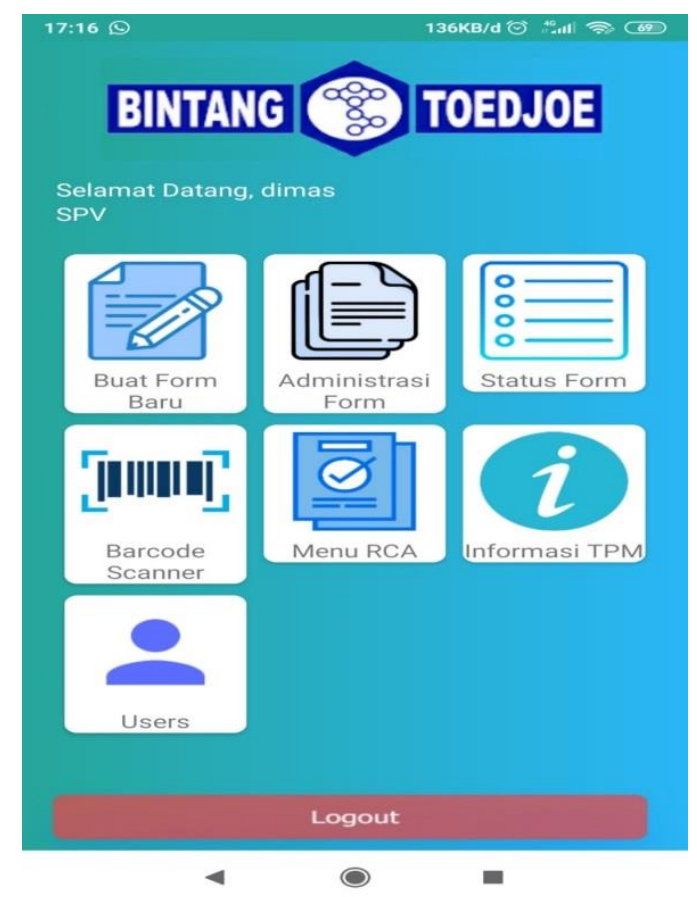

Gambar 3. Tampilan Halaman Menu Utama

Tampilan halaman menu utama setelah user berhasil melakukan login dan akan menampilkan beberapa menu pilihan. Tampilan ini berisi menu yang akan digunakan untuk kegiatan aktivitas total productive maintenance dan pencarian data mesin yang ada di PT Bintang Toedjoe.

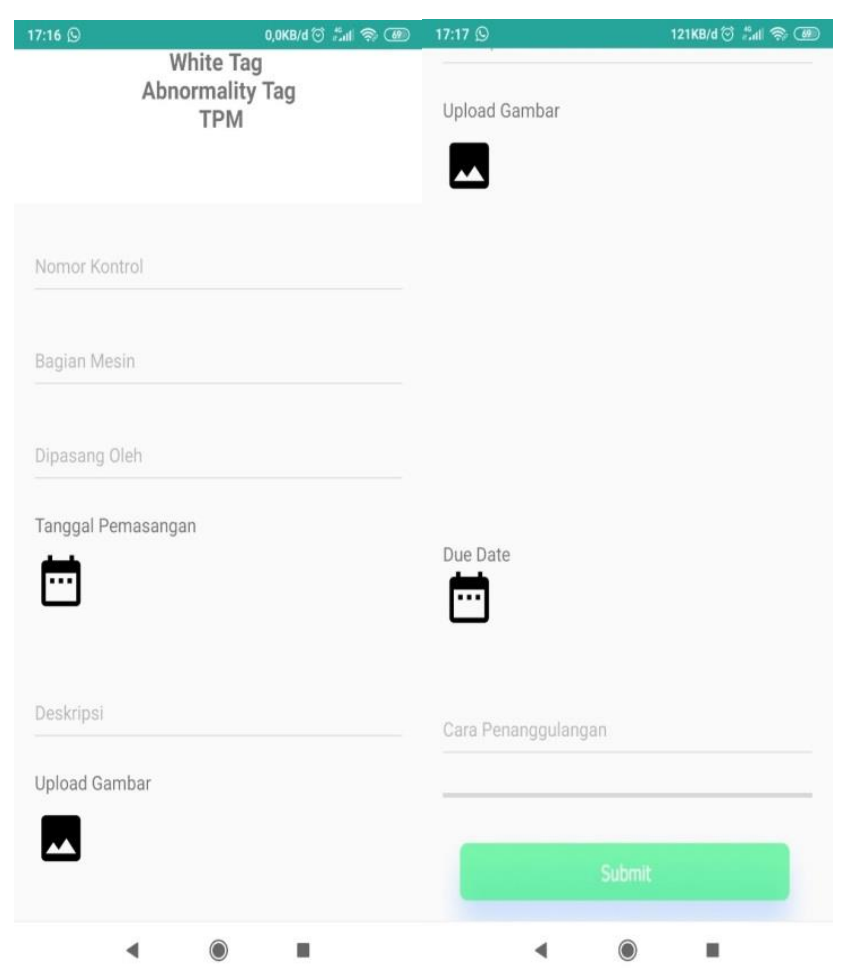

Gambar 4. Tampilan form white tag 
Tampilan form white tag setelah user login dan masuk ke menu buat form baru, sistem akan menampilkan beberapa kolom untuk diisi dan upload foto. Form white tag ini yang akan digunakan untuk kegiatan aktivitas total productive maintenance dan dikerjakan oleh operator.

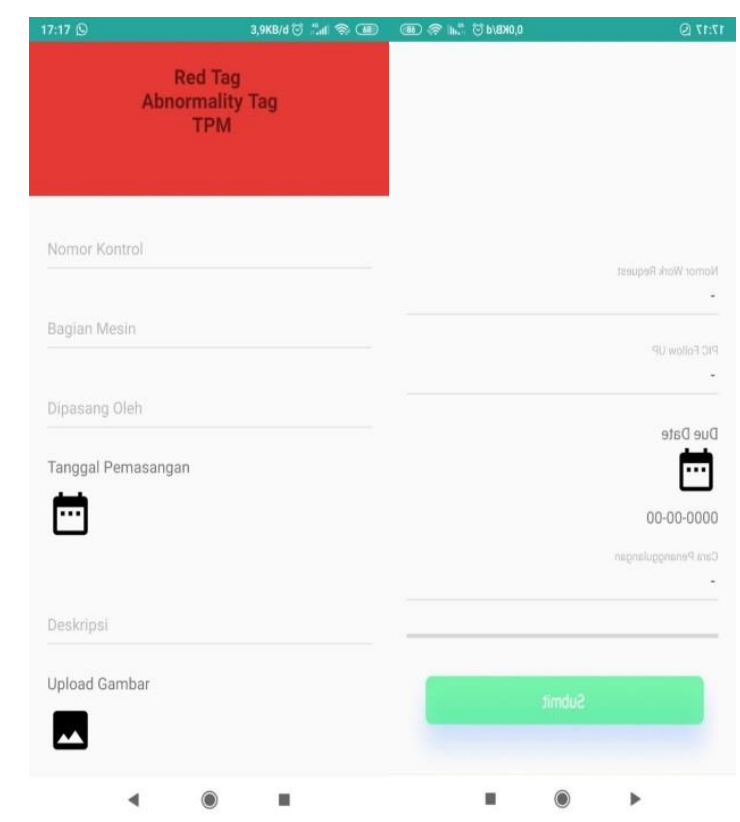

Gambar 5. Tampilan form red tag

Tampilan form red tag setelah user login dan masuk ke menu buat form baru, sistem akan menampilkan beberapa kolom untuk di isi dan upload foto. Form red tag ini yang akan digunakan untuk kegiatan aktivitas total productive maintenance dan dikerjakan oleh teknisi.

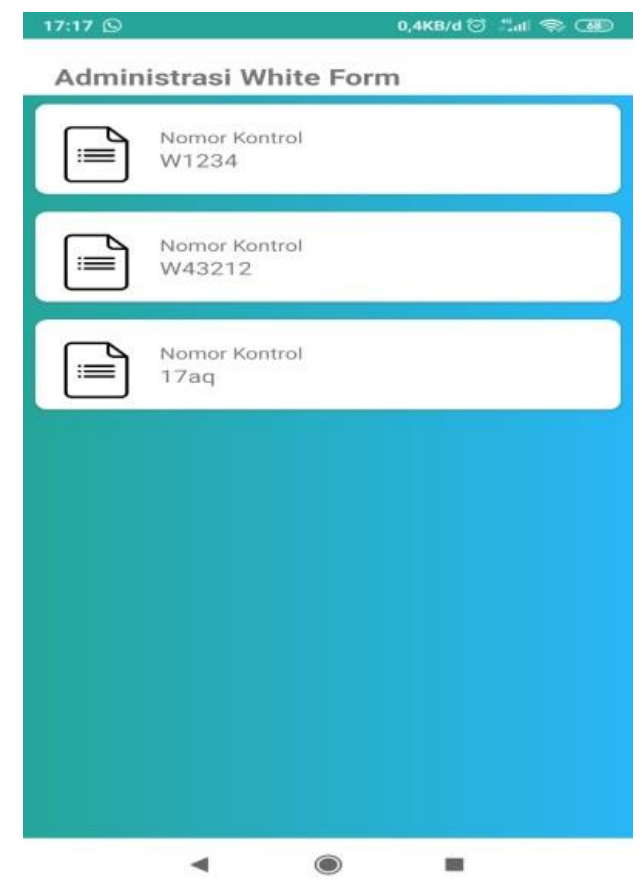

Gambar 6. Tampilan Administrasi Form 
Tampilan adminstrasi form setelah user masuk ke menu utama dan memilih adminstrasi form. Sistem akan menampilkan beberapa list form yang di dalamnya terdapat kolom untuk keterangan form white tag atau form red tag yang telah di buat atau di input ke sistem tersebut. Form bisa di edit serta nantinya di download kemudian print untuk di tempel di mesin yang sedang bermasalah sebagai status informasi pada waktu berjalannya produksi atau kegiatan aktivitas total productive maintenance.

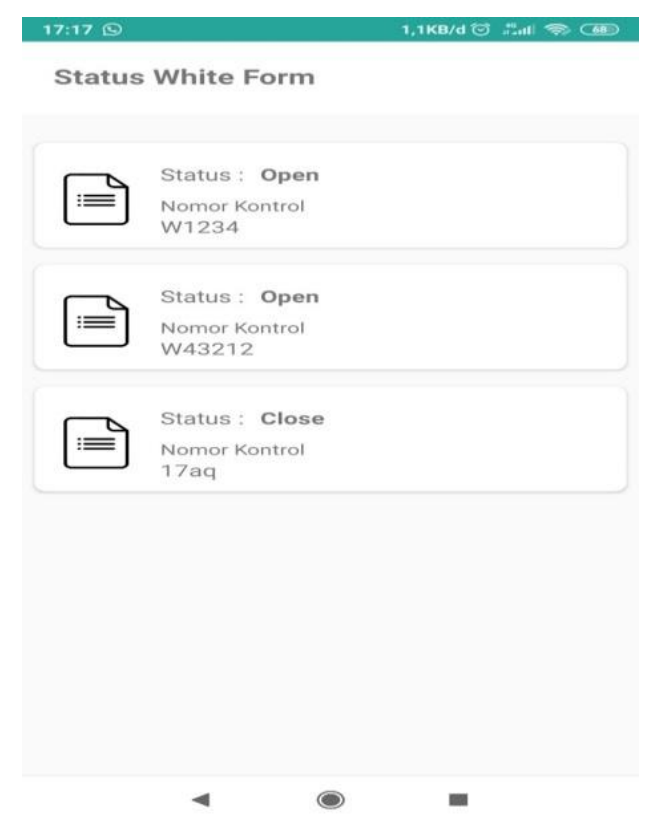

Gambar 7. Tampilan Status Form

Tampilan menu status form setelah user login ke menu utama dan memilih menu status form. Menu ini berfungsi untuk mengetahui sejauh mana form white tag atau form red tag tersebut apakah masih open menunggu untuk perbaiakan, atau sedang proses perbaikan maupun telah close karena telah selesai di perbaiki. Hal tersebut sebagai salah satu data administrasi keterangan mesin produksi pada waktu kegiatan aktivitas total productive maintenance berjalan.

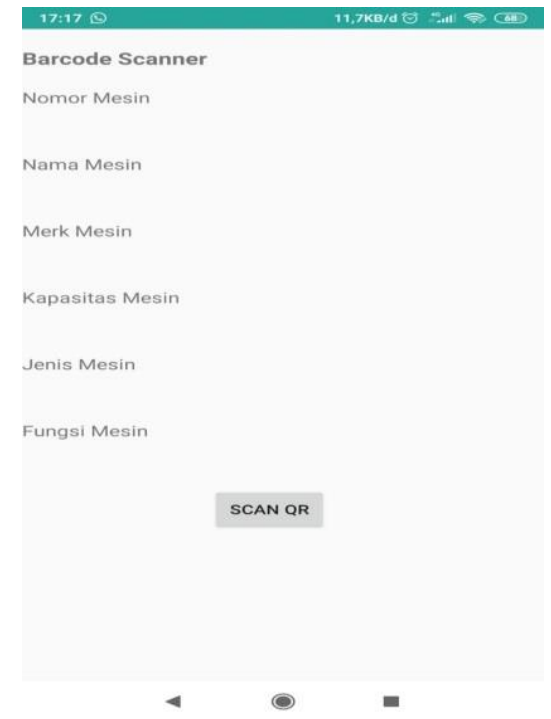

Gambar 8. Tampilan Barcode Scanner 
Tampilan setelah user berhasil login dan memilih menu barcode scanner, sistem akan menampilkan beberapa kolom keterangan mesin yang berfungsi sebagai identitas mesin. Fitur ini membantu user untuk mengetahui indentitas mesin yang ada di produksi dengan cara memilih scan QR, kemudian user melakukan scan barcode atau kode QR yang tertempel di setiap mesin produksi yang ada di PT Bintang Toedjoe Jakarta.

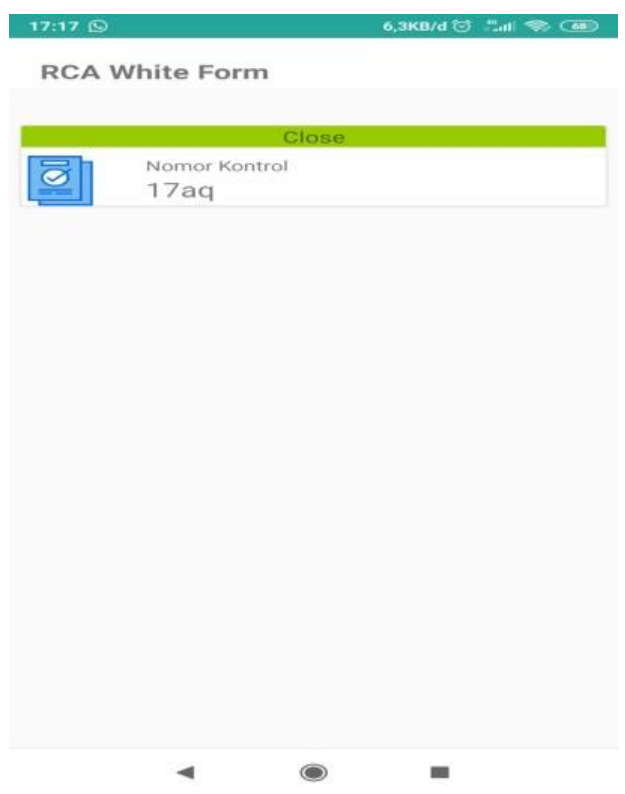

Gambar 9. Tampilan Menu RCA

Tampilan setelah user berhasil login dan memilih menu RCA atau road cost analysis, sistem akan menampilkan beberapa daftar list dari form white tag atau form red tag yang telah selesai. Fitur ini membantu user untuk mengetahui detail perbaikan apa saja yang telah di lakukan pada mesin-mesin yang ada di produksi pada waktu kegiatan aktivitas total productive maintenance berlangsung. Biasanya fitur ini sebagai data dari admin TPM dan manager plant manufacture di PT Bintang Toejdoe Jakarta.

\section{KESIMPULAN DAN REKOMENDASI}

Berdasarkan uraian hasil penelitian dapat disimpulkan bahwa perancangan aplikasi B7TPM berbasis android ini dapat membantu mempermudah operator melakukan penginputan dan pendataan apa saja yang harus di perbaiki dan diganti ketika aktifitas TPM berlangsung. Ketika terjadi pergantian shift, operator dan teknisi di shift berikutnya akan sangat terbantu dengan adanya label informasi yang jelas pada setiap mesin produksi dan bisa mengetahui sejauh mana mesin tersebut diperbaiki apakah belum dipegang teknisi, atau masih proses perbaikan, maupun sudah selesai. Hal itu dimungkinkan karena terdapat keterangan pada status mesin produksi tersebut. Perancangan aplikasi ini juga di anggap efektif oleh manajer produksi dan tim IT karena memanfaatkan tablet yang ada di 
setiap ruang produksi serta menggunakan database perusahaan yang aman karena menggunakan koneksi LAN dengan lingkup hanya di internal area perusahaan saja. Jaringan tidak bisa diakses dari luar lingkungan kantor PT Bintang Toedjoe Jakarta.

\section{REFERENSI}

Danuseputro, C. A. (2016). Aplikasi TPM (Total Productive Maintenance) Pada Produksi Line 3 PT. HJL Untuk Meningkatkan Efektivitas Produksi. Widya Mandala Catholic University, Surabaya.

Kurniawan, F. (2013). Manajemen Perawatan Industrik, Teknik dan Aplikasi. Yogyakarta: Graha Ilmu.

Sudrajat, A., \& Rahmatullah, G. M. (2020). Pedoman Praktis Manajemen Perawatan Mesin Industri Ed. Revisi. Bandung: Refika Aditama.

Utomo, G. A., \& Alghofari, A. K. (2018). Penerapan Total Productive Maintenance (TPM) dan Six Big Losses untuk Meningkatkan Efektivitas dan Efisiensi pada Mesin Injection Molding Nigata (Studi Kasus: Asia Protendo Graha). Surakarta. 